\title{
Cookery academia
}

\section{Culinary collections in libraries grow up, and out}

\author{
by Jim Morris-Knower
}

I n June 1999, a man named Robert Barth of Salt Lake City contacted Cornell University's Mann Library about the cookbook collection of his friend Thomas Bass. Bass had recently died, and his will expressed his interest in donating his entire collection-nearly 2,000 volumes-to Mann. Would the library be interested?

That summer, a retired Mann librarian, now living in Utah, sifted through the collection and determined that it would indeed be a valuable addition to the library's holdings and worth the $\$ 600$ to ship it to Cornell.

Why would someone with no connection to either Cornell or Mann bequeath his cookbooks, worth thousands of dollars, to us? "During the last year of his life, Tom told me several times that Mann Library at Cornell University was the only library he knew that had a specific interest in historic American cookbooks," Barth explained. "He wished to give the library his collection should anything happen to him. He dreaded the idea of his collection falling into the hands of professional dealers and being sold piecemeal to the highest bidder."

A year after the Thomas Bass Cookbook Collection was established at Mann Library, I set out to write a brief profile of this collector and his cookbook collection. As I started to do a little background research for the article, I quickly realized several things. One was that Tom Bass was wrong in believing that Mann was the only library with a historical interest in cookbooks. Another was that he was right in wanting to preserve his collection by donating it whole to a library; the market for vintage cookbooks, I found out, is hot. And the third was that I was wrong in thinking this article could be simply about one man and his cookbooks.

My "brief profile" idea was shot as soon as I stumbled on "A Selective Guide to Culinary Library Collections," an 81-page document prepared for the International Association of Culinary Professionals. ${ }^{1}$ The guide identifies 60 institutions "with significant library collections related to the culinary field." There are 15 public libraries in the guide, 9 historical associations, 31 academic libraries, 4 culinary school libraries, and 4 federal government libraries.

Not only are there a lot of excellent culinary collections out there, but most of them have grown significantly or been formed in the past 15 years. What we were experiencing at Mann-an acquisition significantly expanding our holdings in cookery and gastronomy - was going on around the country.

Here is a sampling of what I discovered:

- In December 1990, Radcliffe's Schlesinger Library announced that Julia Child had donated to them her collection of French and American cookbooks, tapes of her TV series The French Chef, and her papers. Today, Radcliffe's culinary collection is one of the world's largest at more than 22,000 volumes.

- In 1991, the American Institute of Wine and Food, a national organization founded by Child and vintner Robert Mondavi, divided its rare book

\section{About the author}

Jim Morris-Knower is public senvices librarian at Cornell University's Albert R. Mann Library, e-mail: jpk15@cornell.edu (1) $2004 \mathrm{Jim}$ Morris-Knower 
collection between Radcliffe and the University of California-San Diego (UCSD). The initial gift to UCSD of 364 volumes established their collection.

- In April 1996, 200 people gathered at the University of Pennsylvania's Van-Pelt Dietrich Library to celebrate the opening of the Esther B. Aresty Collection of Rare Books in the Culinary Arts. The 576 books and 13 manuscripts include a Venetian manuscript from 1475 , reputed to be the first cookbook ever printed.

- In 2002, New York University acquired the library of Cecily Brownstone, the Associated Press's food writer for 40 years and a close friend of $J o y$ of Cooking author Irma Rombauer. The collection, with 8,000 volumes and 50,00 pamphlets, contains 15 different editions of the Joy of Cooking and the entire correspondence between Brownstone and Rombauer.

\section{Why cookbook collections are in}

Obviously, Mann was not alone in cooking up a major culinary collection in the late 20th century. But the more interesting question remains - why? Why are these cookbook collections expanding faster than a soufflé in a convection oven?

There seem to be three major social forces connected to this expansion. While I'm still not absolutely certain which is cause and which is effect, it's clear that the rise of academic culinary collections is tied to a growth in our culture's obsession with food, a growth in the antiquarian market for vintage cookbooks, and a growth in academia's scholarly interest in food.

Of these phenomena, the most obvious is that we have gone food crazy. You can see this on television, where once there were scattered food programs like the Galloping Goumnetand today there is an entire cable channel, the Food Network, serving up nothing but food programming 24 hours a day. You can also see this on magazine racks offering a spread of glossy food periodicals; the once elite foodie magazine Goum $\mathrm{met}$ is now positively mass-market with over a million subscribers, and its rival Food and Wine is even bigger.

Our fascination with all things bon appetite is not simply with the craft of creating, either, but also with the politics of eating. The big surprise in the publishing world in 2002 was the runaway popularity of Fast Food Nation, journalist Eric Schlosser's indictment of our country's love of fried, supersized meals.

The Slow Food movement, started in 1985 in Italy as a protest against a proposed installation of a McDonald's in Rome, has grown to 65,000 members across 42 countries dedicated to preserving traditional, slower ways of preparing and enjoying food. And a recent poll by the Center for Science in the Public Interest showed that two-thirds of Americans support the labeling of genetically modified food and more than three quarters want food sprayed with pesticides to be labeled accordingly. Clearly we're becoming more interested in what goes in our mouths.

Not surprisingly, this growing concern with what we eat is also seen in an increased interest in buying and collecting books on the topic. The market for vintage cookbooks, for example, has grown rapidly during the same period that cookbook collections in libraries have expanded.

In 1999, a Wall Street Joumal article noted that "antique cookbooks are soaring in value, perhaps the hottest sector in the rare book field." How hot? A 1796 edition of Amelia Simmons' American Cookery, considered the first truly American cookbook with recipes for things like pumpkin pie and Johnny Cake, fetched $\$ 22,000$ at an auction in the 1990s. A first edition of the kitchen staple Joy of Cooking, published in 1931, is today worth more than $\$ 3,000$. And even Jell-O booklets, which came free with boxes of Jell-O in the early 20th century, can go for $\$ 100$ a pop.

\section{The rise of food studies}

If cookbooks are the hottest sector in the rare book field, food studies is the hottest subject in academia. More art and less science than you find in a traditional food science or nutrition program, and not really concemed with learning to cook either, food studies instead focuses on the cultural, symbolic, and ideological meanings of what we cook and eat. And now, it seems, everyone in academia wants a piece of it.

"I'm thrilled [with the rise of food studies], because I've been teaching food and culture for 30 years and have always had to struggle with people saying 'but it's just food,"' says University of Pennsylvania folklorist Janet Theophano, who curated an exhibit from the Aresty Collection when it first came to Penn. "Now, even the most esoteric and elite of disciplines-like literary studies - are involved."

Food studies departments and programs are sprouting up everywhere. In 1997, New York University's Department of Nutrition changed its name to the Department of Nutrition and Food Studies. Boston University and George Washington University have also started such programs 
recently, and many other colleges and universities are offering classes on food.

Witness too the spawning of scholarly food studies journals and university press series. Journals like Food and Foodurays, The Joumal of the Asso ciation for the Study of Food and Society, and Gastronomica: The Journal of Food and Culture were all launched in the last 15 years. For the book minded, both the University of Illinois Press and the University of California Press now have food studies series with monographs on everything from food rationing in World War II to humans eating great apes in Africa.

As all these examples make clear, the growth of academic cookery collections is not occurting in a vacuum, but is directly connected to a growing interest in both the contents and meaning of what we eat. Some of the directors of culinary collections I spoke to were quite aware of these connections; one of the more perspicacious (and ambitious) is Peter Berg, head of special collections at Michigan State University (MSU). Berg has taken what was originally a small home economics collection and transformed it into a 7,000volume culinary repository with its own endowment. In 2002, he partnered with MSU's museum to create "Feeding America," an IMLS-funded online collection of the most important 19th and early 20 th century American cookbooks. ${ }^{2}$

Berg understands both the context of the growth of culinary library collections and the implications of that growth for libraries. "More than a few (of these collections) seem to be the result of major gifts, and these gifts are being accepted and other collections are being built because the study of food and food culture has become acceptable, even desired, among scholars in academia," he says. "Of course, foodways and cookbooks have always had a special place among people outside the university who provide support through donations and use."

\section{New opportunities}

Thus not only are college and university libraries building and expanding culinary collections to serve academics with a new appetite for food studies, but they are also using these collections to create opportunities to reach new patrons outside the ivory tower while increasing financial support. The area of keen interest here for libraries is the intersection of collection development, patron development and, well, development development.

At the University of Pennsylvania, the Aresty collection is serving as the focus for publicitygenerating food programs, such as the 2002 exhibit of some of Philadelphia chef Fritz Blank's 10,000 cookbooks, launched in tandem with a series of talks tied to the exhibit. The opening night gala had hundreds of people eating Geman potato salad and Viennese pickled herring while listening to Blank discuss how to make old recipes work. The exhibit and program series attracted a large and very mixed audience of gourmands from both the city and the university.

"The Aresty collection gave us something we could use to build new constituencies, and we have been trying to take advantage of it," says Special Collections head Michael Ryan. "Cookbooks are one of those useful bridges that span the academic and the lay sides of our world."

Radcliffe's Barbara Haber also knows about such dances, the win-win relationships that generate publicity and suppoit for the library. Haber, recently retired as Schlezinger's director, started the Radcliffe Culinary Friends the same year Julia Child gave her cookbooks to the library. The Friends put on culinary programs featuring Boston-area food writers and scholars, publish a newsletter, and throw an annual Christmas book sale that generates $\$ 4,000$ for the library in one day. All of this raises the profile of both the library and Haber ("I'm in a lot of Rolodexes," she says), while generating funding for the collection.

Haber is also on the foundation of the IACP, the group responsible for the guide to culinary library collections I found so useful. In fact, she wrote the first edition of the guide, the first component of a broader plan to teach people how to do culinary research. "I didn't want to simply be on a board to raise money to send kids to cooking school," says Haber, explaining her work. The second part is a national campaign to preserve cookbooks, something that got off the ground last year when KitchenAid donated $\$ 25,000$ to the cause, know formally as "Endangered Treasures." The first cookbook scheduled for preservation is a copy of American Cookery, held at UCSD.

Tom Bass would, I'm sure, be happy about all of this growing interest in cookbooks and the way libraries are using them in programs and projects that attract lots of people and lots of attention. And he certainly would be pleasantly surprised that so many libraries across the country are building up their collections in response to an increased recognition of the social and historical importance of these books.

(continued on page 201) 
covers topics related to bookbinding. The Web site includes subscription information. Also listed are back issues (from 1978-01) available for purchase. Access: http:// www.bindersguild.org.

- Dog Eared Magazine: A Journal of Book Arts. This magazine's site provides a helpful

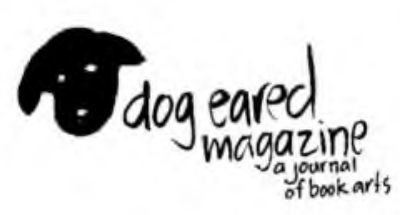
online resource guide of further information and Web links for each published issue.

Although the full text of articles is not available online, the site does feature listings of article topics, tables of contents for issues, and back issue and subscription information. Access: http://www. dogearedmagazine.com.

- Letter Arts Review. This publication is a magazine for calligraphers and letter artists. Its Web site does not offer full text of articles. However, the site does offer a cumulative article index, summaries and images from current issues, subscription information, and details for ordering back issues. In addition, the site features many color photos of calligraphy in its "Pic of the Week" section. Access: http://www. johnnealbooks.com/lar/index.htm.

- The Microbibliophile. This journal "features articles about miniature books new and old, reviews of newly published miniature books, as well as announcements about events relating to the world of the little book." The journal's Web site does not provide full text of articles, but does offer contact and subscription information. ACcess: http://www.microbibliophile.com/.

- Umbrella. The articles in this publication focus on news about and reviews of attists' books. The companion Web site to the journal offers archived articles in Adobe PDF format available from 1997 to 2001. More recent articles from 2002-03 are available selectively. Access: http:// colophon.com/umbrella/index.html.

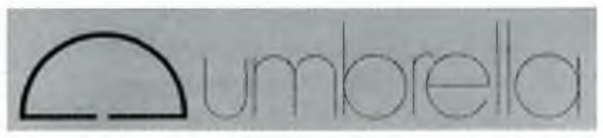

\section{Electronic lists/discussion groups}

- BOOKARTS-L. Sponsored by the Book Arts Web, this discussion group focuses on all book arts topics. To join this group, send the message "subscribe Book_Arts-L Your REAL Name" to listserv@listserv.syr.edu. Details available at: http://www.philobiblon.com/.
- Cyberscribes: The Premier Internet Calligraphy Discussion Group. Around since 1995, this electronic list concentrates on calligraphy-related topics. The list's Web site includes a history of the list and instructions on how to join. Access: http://www.calligraph.com/ cyberscribes/.

- GBW Listserv. This list is sponsored by the Guild of Bookworkers (GBW) and is open to GBW members only. An FAQ, archives, and instructions for joining are available at: http://palimpsest. stanford.edu/byform/mailing-lists/gbwlist/.

- LETPRESS. This group discusses issues related to letterpress printers and printing. To join this group, fill out the subscription form at http://hermes.csd.unb.ca/bin/wa?SUBED1= letpress\&A=1.

- Yahoo! Groups-Book Arts. Yahoo! Groups presents a diverse group of approximately 85 book arts discussion groups ranging from "alteredbooks" to "PPLetterpress." Each group's listing provides a summary and rules and instructions for joining. Access: http://dir.groups. yahoo.com/dir/Entertainment_Arts/Fine_ Arts/Design_Arts/Book_Arts.

\section{Notes}

1. See the following discussions from the Book_Arts-L discussion list: "Definition of the Artist's Book; What is a Book; BSO's (Book Shaped Objects); Art vs. Craft" at www.philobiblon. com/whatisabook.htm and "The Whatness of Bookness, or What is a Book" at www.philobiblon. com/bookness.htm.

2. Alisa Golden, Creating Handmade Books (New York: Sterling Publishing Co., Inc., 1998), 19.

\section{("Cookery academia" continued frompage 197)}

Of course, it was to Cornell's benefit that he didn't know too much; after all, all those Jello-O pamphlets we got might have ended up at someplace like University of Pennsylvania instead.

\section{Notes}

1. See www.iacpfoundation.com/docs/ culdir.pdf for the IACP document "The Selective Guide to Culinary Library Collections in the United States."

2. See digital.lib.msu.edu/cookbooks for MSU's "Feeding America: The Historic American Cookbook Project." 